\title{
Natureza e cultura no Porto do século XIX
}

\author{
Helena Madureira1, 2 \\ José Ramiro Pimenta1, 3 \\ 1 CEGOT - Centro de Estudos em Geografia e Ordenamento do Território \\ 2 hmadureiramail@gmail.com; 3 jose.ramiro.pimenta@gmail.com
}

\section{RESUMO}

A estruturação social de uma cidade pode inferir-se da morfologia e estrutura dos espaços verdes. Partindo de uma carta da cidade do Porto (Portugal), de 1892, procedeu-se ao reconhecimento dos contextos tipológicos e espaciais da estrutura verde em finais do século XIX: i) cidade intramuros; ii) a área de expansão extramuros, de forte ampliação nos séculos XVIII e XIX iii) anel periférico rural, suporte do desenvolvimento urbanístico ao longo do século XX. A modernização da cidade resulta no encontro e conflito entre a produção do espaço e da natureza, a representação das suas paisagens e a prática concreta dos seus lugares.

\section{ABSTRACT}

The social structure of a city may be inferred from the morphology and arrangement of green areas. Drawing on a 1892 map of Porto (Portugal), typological and spatial contexts of its green structure were delineated: i) the walled medieval city core; ii) the outer-wall expansion area $\left(18^{\text {th }}-19^{\text {th }} \mathrm{cs}.\right)$; iii) a peripheral rural belt, where $20^{\text {th }} \mathrm{c}$. urban growth occurred. The modernization of the city is therefore related to the asserted and contested relation between production of space and nature, landscape representation and places of social practice. 


\section{Revista Convergência Crítica \\ Núcleo de Estudos e Pesquisas em Teoria Social - NEPETS

\section{Introdução}

Este estudo sobre o Porto oitocentista privilegia a estruturação social da cidade, a sua vida de relação e as expressões de representação que se podem inferir da morfologia e estrutura dos espaços verdes (Cosgrove 1998). A «Carta Topographica da Cidade do Porto» publicada em 1892 sob a direcção de Telles Ferreira e considerada a primeira planta rigorosa, com levantamento à escala 1:500, que abrange a totalidade do concelho (CMP 1992), constitui o ponto de partida para o reconhecimento da estrutura verde do Porto em finais do século XIX. A planta de Telles Ferreira (Figura 1) ilustra uma forte presença da natureza na cidade, podendo-se evidenciar três principais anéis que, com centro no núcleo central da cidade, vão evidenciando contextos tipológicos e espaciais bem contrastados, associados a diferentes épocas de desenvolvimento: um núcleo central densamente construído, correspondente à cidade intramuros; a área de expansão extramuros, de forte ampliação nos séculos XVIII e XIX; e o grande anel periférico, ainda profundamente rural, que constituirá o suporte do intenso desenvolvimento urbanístico ao longo do século XX. Independentemente deste núcleo em expansão, a franja marítima da cidade e sobretudo o núcleo urbano de $\mathrm{S}$. João da Foz encontravam-se também densamente edificados.

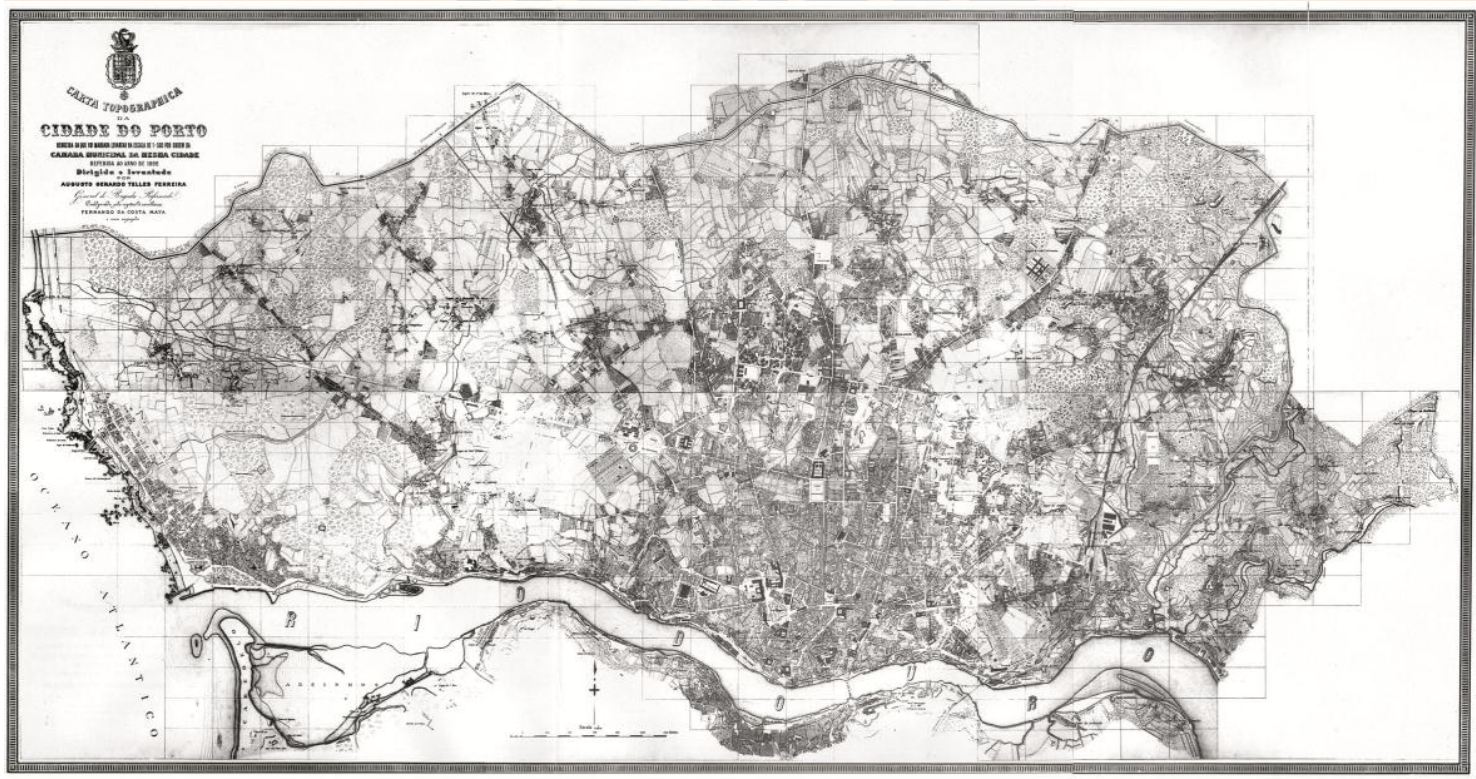

Figura 1 - 'Carta Topographica da Cidade do Porto' de Telles Ferreira (escala original:1:5000)

\section{Cidade antiga}

O núcleo central da cidade, densamente edificado, encontra-se praticamente desprovido de cobertura vegetal, destacando-se apenas pequenos e íngremes quintais nas traseiras dos edifícios, nas cercas de alguns conventos e seus respectivos terreiros e na declivosa encosta do Douro. Correspondendo genericamente à antiga cidade muralhada, este núcleo reproduz uma secular relação entre a cidade e a natureza baseada numa íntima relação espacial e funcional entre o espaço urbano sucessivamente densificado e uma envolvente rural que assegurava o fornecimento diário de frescos à cidade. Junto das portas da cidade localizam-se os "campos", locais de mercado e de encontro, que sobreviverão ao progressivo crescimento urbano, 


\section{Revista Convergência Crítica \\ Núcleo de Estudos e Pesquisas em Teoria Social - NEPETS \\ ISSN 2238-9288}

transformando-se nos principais jardins públicos do centro da cidade da actualidade. A Praça do Infante emerge como o único espaço verde público, ocupando as antigas cercas dos conventos de S. Francisco e S. Domingos (Figuras 1 e 2).

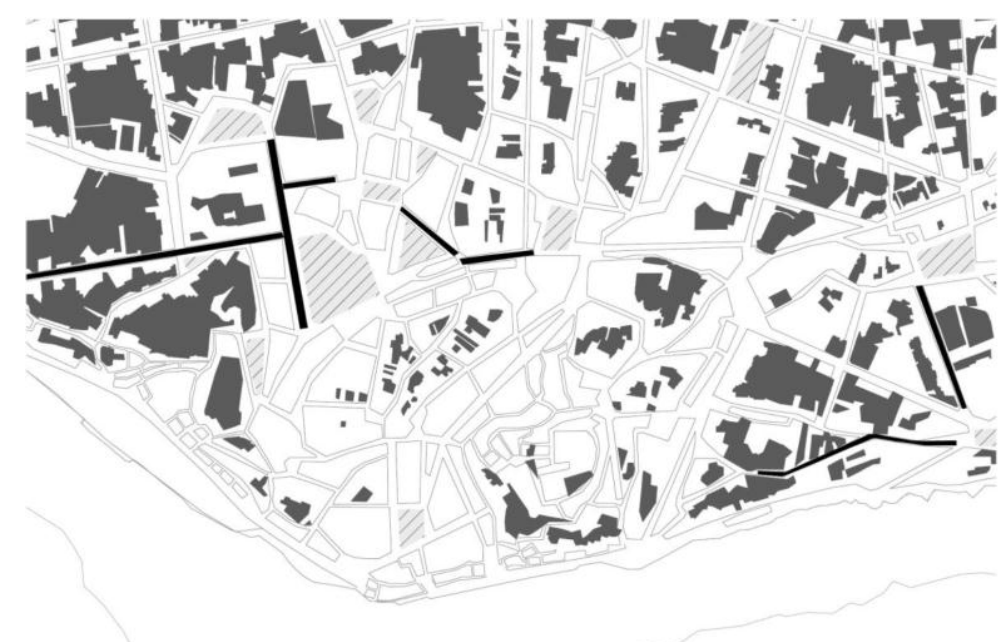

verde agrícola @verde arborizado ou arbustivo 国jardins públicos $\square$ verde associado à edificação @ruas arborizadas

Figura 2 - Porto: a 'cidade antiga'. (Fonte: Madureira 2001-2002, adaptado)

No século XIX, o centro da cidade, que fora a cidade medieval dentro dos muros que se haviam grandemente desmantelado com as obras dos Almadas, não possuía quase nenhuma expressão de natureza vegetal. Essa, de resto, era uma condição que não era nova, pois o elemento de natureza que se lhe associa mais intimamente (se quisermos usar da classificação materialsimbólica de Schama [1995] - água, madeira e pedra) sempre havia sido o elemento mineral.

Em termos de representação simbólica da paisagem urbana (Cosgrove, Daniels 1988), tal não significa uma "ausência de natureza" mas antes a sua expressão liminar. O sítio genético do Porto, comparável a tantos outros que existem na Europa de povoamento mais antigo, mais mediterrâneo do que continental, e como quase todos os principais núcleos urbanos importantes em Portugal, é um sítio de "acrópole", uma localização original alcandorada numa elevação de acesso difícil, com propósitos de defesa e salubridade, distanciado um pouco do mar que lhe fica perto mas a que não pertence e dominando visualmente um rio de que depende em muitos sentidos, entre os quais o de direito de portagem não é decerto o de menor importância, e a cujo "porto" se liga por azinhagas que descem a encosta íngreme para pôr em contacto o centro de poder e a vida vibrante do comércio - um pouco como o modelo que a polis grega havia perpetuado.

De que natureza podemos então falar em relação a esta área central da cidade, sobretudo no contexto da modernização do século XIX? Em certo modo, o mesmo sentido que ainda hoje esse espaço cumpre na cidade actual; uma natureza liminal, indómita, uma penha ventosa com escassa cobertura vegetal a que a gemoforfologia impede maior exuberância e que nessa condição se mantinha ao longo de todo o século XIX como que rememorando uma muralha primitiva que isolava o burgo fortificado do espaço que lhe era exterior, um espaço de wasteland que antecipava o ager que alimentava o centro e se organizava além dele mas por ele. 


\section{Revista Convergência Crítica \\ Núcleo de Estudos e Pesquisas em Teoria Social - NEPETS \\ ISSN 2238-9288}

\section{Cidade nova}

A "cidade nova" corresponde ao anel envolvente do núcleo antigo da cidade, resultando genericamente da consolidação da malha urbana desenvolvida pelos Almadas em finais do século XVIII, densificada ao longo do século XIX, e do crescimento urbano espontâneo ao longo dos eixos de ligação regional. Nesta "cidade nova" surgem significativos espaços com cobertura vegetal de características tipicamente urbanas: os mais representativos jardins públicos e o verde associado à edificação, englobando os logradouros do interior dos quarteirões e os jardins das residências unifamiliares. Na envolvente desta "cidade nova", já em contacto com a periferia rural, onde têm o máximo da sua representatividade na cidade, surgem alguns exemplos de quintas de recreio (Figuras 1 e 3 ).

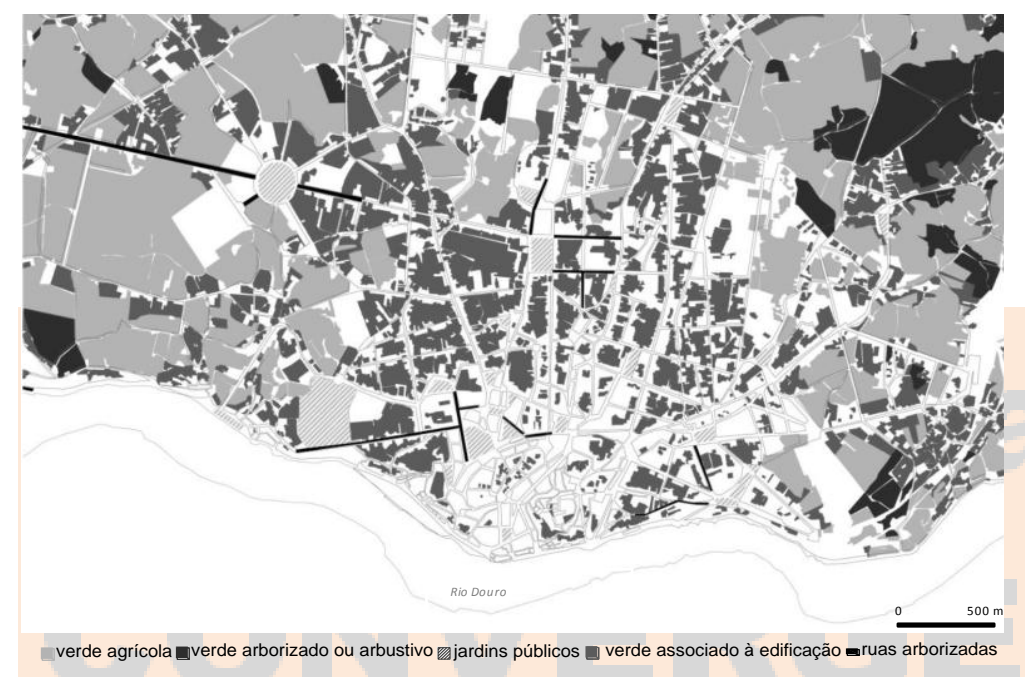

Figura 3 - Porto: a 'cidade nova' (Fonte: Madureira 2001-2002, adaptado)

\subsection{Jardins públicos e ruas arborizadas}

Os jardins públicos, entendidos como elementos morfológicos com identidade e desenho bem definidos, predominantemente revestidos por vegetação e aptos para a prática generalizada de actividades de lazer, definem, em conjunto com as ruas arborizadas, o sistema verde de utilização pública de uma cidade.

Ao longo dos séculos XVIII e XIX a cidade tinha assistido à criação de variadas alamedas, espaços lineares com alinhamentos de árvores geralmente vedados e implantados estrategicamente sob o ponto de vista cénico, às quais não se aplica propriamente o conceito de jardim público (Andresen e Marques 2001). Como exemplos destes primórdios dos jardins públicos destacam-se as alamedas enquadradas na malha urbana - Olival, Lapa, Aguardente, Bonfim, Prado do Repouso - e aquelas implantadas como varandas sobre o Douro - Virtudes, Fontainhas, Massarelos.

O surgimento dos jardins públicos no Porto, tal como na generalidade das cidades europeias, enquadra-se no contexto das amplas transformações decorrentes da Revolução Industrial. Argumentos de cariz social e higienista concorrem para a apologia do jardim público enquanto elemento da forma urbana capaz mitigar os problemas ambientais e sociais que se vinham a colocar nas cidades, perspectivando-o como um instrumento de reforma social. O jardim público era visto como elemento mitigador das condições insalubridade em que vivia a 


\section{Revista Convergência Crítica \\ Núcleo de Estudos e Pesquisas em Teoria Social - NEPETS \\ ISSN 2238-9288}

crescente população urbana e, simultaneamente, como elemento moralizador dessa mesma população, cada vez mais consciencializada das suas próprias más condições de vida. A popularização do jardim público é também o reflexo da ascensão de uma burguesia dotada de poder financeiro e político, com grande influência nas transformações urbanas da época, e que visava reproduzir hábitos de lazer até então confinados à aristocracia. Horácio Capel descreve essa profunda alteração patente tanto nos modos de produção como de usufruto dos jardins (2002, p.5):

Hasta el siglo XVIII los jardines eran, de hecho, paraísos privados, construídos por la realeza, la aristocracia y, más tarde, la burguesía, para su uso particular. Lugares para el descanso y el retiro deleitoso, para la alegría privada y el juego amistoso, para la ostentación y el reposo. Y será ése precisamente el paraíso que en el siglo XIX será accesible para todos, convirtiéndose en el jardín municipal.

O período temporal do surgimento dos primeiros jardins públicos no Porto coincide com novas dinâmicas espaciais e uma noção mais alargada da escala da cidade, reflexos nomeadamente da necessidade de acomodar uma sempre crescente população residente e do desenvolvimento dos transportes urbanos. A cidade foi-se desprendendo do seu núcleo originário centrado na Praça da Ribeira e no rio e incorporando novas áreas de expansão para onde progressivamente convergiam a vida social e económica (Oliveira 1973). É nesta "cidade nova" que se implanta a quase totalidade dos principais jardins públicos, normalmente resultando do ajardinamento dos antigos locais de feira ou de exercícios militares, os campos, que se localizavam junto das portas da cidade ou ao longo das principais vias de ligação à envolvente regional.

Na planta de Telles Ferreira é visível, logo nas imediações do núcleo central da cidade, um sistema relativamente consistente de praças ajardinadas, onde se destacam os jardins públicos de S. Lázaro e da Cordoaria. O jardim de S. Lázaro, antigo campo de feira arborizado, foi inaugurado em 1834 e concluído em 1841. A sua construção terá ficado a dever-se à intenção de D. Pedro IV de fundar uma biblioteca no antigo Convento de Santo António, reconhecendo-se a necessidade de melhorar o espaço que o defrontava. Projectado por João José Gomes, caracterizava-se por uma composição geométrica rígida limitada por um gradeamento. Em finais da década de sessenta do mesmo século o jardim sofreu alterações de Emílio David, conferindo-lhe as características de irregularidade do traçado observáveis na actualidade. $\mathrm{O}$ jardim de S. Lázaro emerge como elemento fundamental no desenho de um pequeno sistema de verde público na área oriental da cidade, articulando-se com a Alameda e Passeio das Fontainhas, sistema que será fortemente reforçado, já no século XX, pela arborização dos arruamentos resultantes do loteamento dos Campos de Cyrne.

O jardim da Cordoaria, também um antigo campo, o Campo do Olival, e onde tinha existido a primeira alameda da cidade, foi inaugurado em 1867. Projectado por Emílio David, o jardim da Cordoaria é o elemento central de um dos sistemas de verde público estruturalmente mais consistentes em finais de oitocentos, englobando o Mercado dos Anjos e todo um conjunto de pequenos espaço ajardinados, articulados por uma pequena rede de ruas arborizadas da Restauração aos Clérigos. 


\section{Revista Convergência Crítica \\ Núcleo de Estudos e Pesquisas em Teoria Social - NEPETS

Os jardins da Praça da República, do Marquês e da Boavista, antigos os campos de feira ainda em processo de ajardinamento, inserem-se já na estrutura urbana de desenvolvimento oitocentista e, portanto, numa área que se encontrava relativamente "desdensificada", não tanto pela escala do espaço público mas pela grande dimensão dos quarteirões. Todos estes jardins se encontram intimamente relacionados com o espaço urbano envolvente e na encruzilhada de várias artérias viárias, a que não será alheio o facto de quase todos esses espaços resultarem do ajardinamento de antigos campos de feira situados nas vias de ligação com a envolvente regional, lugares por excelência de centralidade. Associados aos jardins da Praça da República e da Boavista surgem exemplos representativos de arruamentos projectados durante o século XIX que reflectem, ainda que precariamente, a difusão da experiência francesa dos boulevards. A Avenida da Boavista, ligação de natureza estratégica e militar realizada durante a década de sessenta, sobressai como importante eixo continuamente arborizado.

No panorama geral dos jardins construídos no século XIX, o jardim do Palácio de Cristal destaca-se pelas suas características bem diferenciadas. Embora também localizado numa área da cidade já então fortemente urbanizada, a sua implantação, a sua dimensão e as suas características formais aproximam-no da concepção de um "parque urbano", com um claro isolamento do contexto urbano envolvente. O Palácio de Cristal, pensado para albergar exposições e outros eventos, e os seus jardins ficariam concluídos em 1865, sendo inaugurados com a Exposição Internacional Portuguesa. Emílio David, responsável pelo projecto do jardim, aplica-lhe "as novas modas que corriam pela Europa nos domínios do ordenamento e arranjo de espaços recreativos (...) estruturando-o a partir de dois elementos fundamentais: a alameda, e um bosque com circuitos passando por recantos pitorescos a justificarem o arranjo de outros tantos 'sítios de estar' ligados entre si por caminhos ou veredas" (Araújo 1979, p. 14). Substancialmente alterado ao longo dos tempos, nomeadamente pela demolição do antigo palácio de cristal e sua substituição pelo pavilhão dos desportos (1956) e pelas múltiplas alterações nos jardins, o jardim do Palácio de Cristal permanece na actualidade como um dos espaços verdes públicos mais importantes da cidade.

Os jardins públicos permitem compreender a evolução do Porto do século XIX como um processo não apenas de progressiva dominação do espaço mas também como este se acompanha de uma equivalente dominação social. Max Weber usava o conceito werk para designar esta capacidade de intervir, transformar e produzir activamente a sociedade e a natureza pelas instâncias do poder, termo que passaria a Habermas para caracterizar também uma época epistemológica, muito especialmente a modernidade, de conhecimento activo e transformador. E em que sentido nos pode ser útil este conceito neste estudo sobre o Porto do século XIX e da sua respectiva modernização?

Do ponto de vista do carácter simbólico da paisagem, a produção de espaço e natureza associada aos jardins públicos remete para três qualidades - natureza, tempo e género. Desde logo, uma expressão de dominação da natureza, os jardins públicos exibem as espécies e associações vegetais numa ordem que não a que regula a produção do ager cuja intenção é a produção alimentar que garanta funcionalmente a sobrevivência. Neste sentido, um jardim é uma "inutilidade funcional" e garante a sua identidade justamente pela intensidade de apelo ao sublime. Isto envolve uma produção de espaço e de natureza que contempla espécies que 


\section{Revista Convergência Crítica \\ Núcleo de Estudos e Pesquisas em Teoria Social - NEPETS \\ ISSN 2238-9288}

evoquem e despertem o delíquio dos sentidos, a variedade das cores florais, a intensidade de aromas inesperados, o poder táctil dos elementos vegetais, tudo curvado ao prazer da contemplação e do uso estético - portanto a um desnovelamento do tempo.

O domínio do tempo, e a sua expressão em momento de ócio, é uma das expressões mais características da modernização capitalista da cidade e os jardins são também a sua expressão. Apenas acessíveis a uma classe robustecida pelo comércio e pela indústria, esta disponibilidade do tempo encontra nos jardins a sua plena efectivação, pois é aqui que o ócio da classe burguesa se exibe exteriormente na cidade. Os horários de trabalho de um novo funcionalismo público, o robustecimento de uma nova classe média, que os magasins revestem de toilettes de exibição e que suporta e se define pelas novas relações de trabalho - tudo se reunindo no resultado esperado de produção e uso do espaço urbano que são os jardins públicos.

Finalmente, este uso obedece a uma distinta organização de género no âmbito do fortalecimento desta nova classe nascida da urbanização capitalista. As relações domésticas, entre homens e mulheres, adultos e crianças, recompuseram-se, quando comparadas com as do século que terminara em 1800, e de um certo modo estabelecem uma organização da vida doméstica e de relação entre géneros que serão a matriz do século a que pertencem mas também as do masculinismo funcional que penetrará quase todo o século XX.

Os jardins públicos são, por isso, o espaço produzido, a paisagem de representação e o lugar de práticas das relações entre os géneros na sua expressão pública. Quando vemos as gravuras que os representam, e que certamente se reavivavam no recolhimento das paredes de casas particulares desta nova classe média que o século fortalecia, vemos não raramente imagens de enamoramento entre homens e mulheres jovens, ou cenas de amas e jovens mães com os carrinhos-de-bebé, réplicas de pequenos coches; ou crianças, os rapazes equilibrando um pequeno veleiro nas águas quietas de um lago, as meninas, mais pacatamente, empurrando as bonecas numa réplica de réplicas das mães e das amas. Assim, este espaço, que é um espaço produzido para recolher a metade feminil da vida doméstica, é ao mesmo tempo um espaço de "oclusão" - não era tolerada a mobilidade feminina pelas ruas da cidade - e um espaço que, pela prática, refrescava, nas rotinas das horas do dia e do curso das estações, os atributos masculinistas do cortejamento, da família, da vida doméstica - naturalizando assim a interdição da mulher à sensualidade, à independência e ao trabalho.

Desde os escritos de Baudelaire, e a sua revisita por Benjamin (1997), que o boulevard e a sua correspondente ideia de natureza são de comum referência em trabalhos sobre a cidade e a sua modernização. O Porto do século XIX não é com certeza comparável a Paris de fin-de-siècle e, embora tenha recebido múltiplas expressões desse mal de cité que habita os versos de Baudelaire, ou de Cesário em Lisboa, é uma cidade incompleta na produção do espaço de flânerie. Aliás, como em muitos outros elementos da sua modernidade, a cidade do Porto do século XIX (e também em fases mais recentes) é uma cidade de metamorfoses incipientes, subitamente truncadas e sem a radicalidade da transformação a penetrar verdadeiramente a estrutura da cidade. Porém, com as Virtudes, e outros elementos semelhantes, e mais tarde com as ruas arborizadas dos seus quarteirões mais recentes, também a cidade do Porto aderiu, com o 


\section{Revista Convergência Crítica \\ Núcleo de Estudos e Pesquisas em Teoria Social - NEPETS

século da modernização liberal, ao gosto transeunte pelo cénico e adoptou o gosto e o hábito do "passeio" que o era já de nome.

Basta um olhar pelo mapa da cidade dos fins do século XIX, para compreendermos que estes elementos detêm uma expressão mínima na estrutura verde da cidade, como mínimo é também o poder associado dos elementos cénicos edificados. São exíguos os traçados de ruas e os levantamentos de alçados que promovam activamente a distracção deambulante dos habitantes da cidade. Ao longo do século, e apesar da enorme transformação a que a morfologia da cidade é submetida, o mundo rural ainda a penetra profundamente e são de uma aldeia muitas das suas expressões para quem a percorre.

Contudo, existe um elemento novo da cidade em que se concentra este novo modo de débil melancolia em relação à cidade transformada - os cemitérios. Os grandes cemitérios públicos da cidade, então na sua periferia mas hoje engolfados após o crescimento da cidade ao longo do século XX, possuem vários elementos que permitem aproximá-los do espírito do século XIX, quando o cientismo e o romantismo tardio se associam para celebrar o sublime da natureza e a intransiência do tempo. Não é de estranhar a asociação próxima entre o romantismo e o cientismo que se poderiam julgar tão contrários - a ambos os anima uma perda da tranquilizadora presença divina que os séculos anteriores (Shapin 1991) haviam conhecido - e os dois, de certo modo, representam os extremos da relação cultural do século com o relativo sentimento de orfandade.

Estes novos cemitérios possuem assim uma dupla qualidade - pela celebração do sublime da ciência, eles apresentam-se como os impecáveis organizadores da morte dos novos corpos sem alma, rotulando, recenseando e lacrando, numa réplica da cidade dos vivos, com suas ruas, casas e quarteirões, os corpos que a cidade moderna multiplica exponencialmente; contemporâneos das perturbações populares que acompanham o fim do enterramento tradicional nas igrejas e seus adros, os cemitérios do século XIX do Porto são para os mortos da cidade o que o grande hospital construído pelo Conde de Ferreira o é para os alienados, e o que a cidade nova é para os vivos - um espírito positivo de organização da nova ordem urbana, do número, do anonimato, da cidadania.

Porém, os cemitérios são algo mais do que a celebração do sublime da ciência - eles são também, e isso os aproxima do boulevard, o lugar de flânerie (Tester 1995) e de experiência anónima da deambulação, o espaço produzido e representado da brevidade, melancolia e orfandade próprias da condição moderna. Produzido, porque nas ruas que desenha entre as casas-dos-mortos, com suas alamedas e pequenos bosques, promovem o passeio silencioso dos novos urbanitas, não apenas no contexto adequado de um evento fúnebre mas, e principalmente, na possibilidade quotidiana de aí aceder, passeando, como se de um quarteirão mais da cidade se tratasse. Representado porque, associado à produção de natureza vegetal, existe uma iconografia fúnebre que repete em temas diferentes iguais arquétipos que remetem para a condição moderna da nova cidade: a orfandade existencial de um deus já perdido, a intransigente anomia da vida urbana, a submissão inteira da persona ao opus. Não admira, portanto, que a cidade tenha conhecido nesta altura os seus mais notáveis suicidas. 


\subsection{Jardins privados}

O século XIX foi também representativo em termos de construção de jardins privados. A observação da planta de Telles Ferreira dá-nos uma imagem da importância do verde associado à edificação, de propriedade privada, na estruturação global do sistema verde na cidade de oitocentos.

Uma primeira categoria de áreas verdes associadas à edificação corresponde aos amplos logradouros do interior dos quarteirões. Correspondem a uma morfologia urbana característica do Porto, caracterizada por quarteirões de lotes estreitos e fundos que, albergando no seu interior esguios quintais, definem no seu conjunto amplas áreas verdes não percebidas a partir do espaço público da cidade. Esta forte presença dos quintais no interior dos quarteirões é um resultado directo da expansão urbana projectada pelos Almadas no século XVIII e da reprodução mais ou menos generalizada do modelo nas décadas seguintes.

Tendo como objectivos da sua intervenção a definição de novas áreas de expansão da cidade, a construção de novas áreas residenciais no exterior do núcleo medieval para a burguesia mais abastada e melhorar as ligações entre o antigo centro da cidade e esses novos bairros, os Almadas acabaram por ter uma forte influência, ainda que indirecta, na estruturação das áreas verdes urbanas. A adopção de um padrão de loteamento regular, com base num lote de 5,5 metros de largura e geralmente muito comprido, atingindo por vezes os 100 metros (Teixeira 1996), não resultando de qualquer estratégia para o verde urbano, mas antes respondendo a requisitos técnicos e económicos, teve importantes repercussões para a evolução da cobertura vegetal da cidade. Estabelecendo uma morfologia urbana que contempla nas traseiras das edificações amplas áreas livres onde se estabelecem profundos quintais particulares, rompia-se com a densidade de ocupação do núcleo intramuros e formulava-se um modelo que permitia um contacto estreito com a natureza. Ainda durante a segunda metade do século XIX muitos destes interiores de quarteirão foram alvo de processos especulativos pelos seus proprietários, que construiram habitação para a classe trabalhadora nos seus próprios quintais das traseiras (Matos, Rodrigues 2009). As "ilhas", longas filas de casas estreitas de um só andar que se abrem apenas para corredores laterais de acesso construídos ao longo dos logradouros proliferavam em muitos dos interiores de quarteirão outrora ocupados por quintais privados.

Os quintais das residências unifamiliares e as quintas de recreio constituem a outra categoria de áreas verdes associadas à edificação com ampla difusão ao longo do século XIX e evidenciáveis na planta de Telles Ferreira. Surgindo em várias áreas da "cidade nova", como no interior dos quarteirões de Cedofeita, os exemplos mais notórios encontram-se nos extremos orientais e ocidentais da mancha urbana. Tendo em comum a presença de árvores raras e exóticas, ornamentais ou de fruto, os jardins diferenciavam-se de acordo com os seus proprietários. Júlio Dinis, no seu livro Uma Família Inglesa, descreve essas diferenças.

Esta nossa cidade - seja dito para aquellas pessoas, que porventura a conhecem menos - divide-se naturalmente em tres regiões, distinctas por physionomias particulares. A região oriental, a central e a occidental. 


\section{Revista Convergência Crítica \\ Núcleo de Estudos e Pesquisas em Teoria Social - NEPETS \\ ISSN 2238-9288}

O bairro central é o portuense propriamente dito; o oriental, o brazileiro; o occidental, o inglez. No primeiro predominam a loja, o balcão, o escriptorio, a casa de muitas janellas e de extensas varandas, as crueldades architectonicas, a que se sujeitam velhos casarões com o intento de os modernisar; o saguão, a viella independente das posturas municipaes e á absoluta disposição dos moradores das vizinhanças; a rua estreita, muito vigiada de policias; as ruas, em cujas esquinas estacionam gallegos armados de pau e corda e os cadeirinhas com o capote classico; as ruas ameaçadas de procissões, e as mais propensas a lama; aquellas onde mais se compra e vende; onde mais se trabalha de dia, onde mais se dorme de noite. Ha ainda n'este bairro muitos ares do velho burgo do Bispo, não obstante as apparencias modernas que revestiu.

O bairro oriental é principalmente brazileiro, por mais procurado pelos capitalistas, que recolhem da America. Predominam n'este umas enormes moles graniticas, a que chamam palacetes; o portal largo, as paredes de azulejo--azul, verde ou amarello, lizo ou de relêvo; o telhado de beiral azul; as varandas azues e douradas; os jardins, cuja planta se descreve com termos geometricos e se mede a compasso e escala, adornados de estatuetas de louça, representando as quatro estações; portões de ferro, com o nome do proprietario e a era da edificação em lettras também douradas; abunda a casa com janellas gothicas e portas rectangulares, e a de janellas rectangulares e portas gothicas, alguma com ameias, e o mirante chinez. As ruas são mais sujeitas á poeira. Pelas janellas quasi sempre algum capitalista ocioso.

O bairro occidental é o inglez, por ser especialmente ahi o 'habitat' d'estes nossos hospedes. Predomina a casa pintada de verde-escuro, de rôxo-terra, de côr de café, de cinzento, de preto... até de preto! - Architectura despretenciosa, mas elegante; janellas rectangulares; o peitoril mais usado do que a sacada. - Já uma manifestação de um viver mais recolhido, mais intimo, porque o peitoril tem muito menos de indiscreto do que a varanda. Algumas casas ao fundo dos jardins; jardins assombrados de acacias, tilias e magnolias e cortados de avenidas tortuosas; as portas da rua sempre fechadas. Chaminés fumegando quasi constantemente. Persianas e transparentes de fazerem desesperar curiosidades. Ninguem pelas janellas. Nas ruas encontra-se com frequencia uma ingleza de cachos e um bando de creanças de cabellos louros e de babeiros brancos.

Taes são nos seus principaes caracteres as tres regiões do Porto; sendo desnecessario acrescentar que n'esta, como em qualquer outra classificação, nada ha de absoluto. Desenhando o typo especifico, nem estabelecemos demarcações bem definidas, nem recusamos admittir algumas, e até numerosas excepções, hoje mais numerosas ainda do que então, em 1855.

As "casas brasileiras", com os seus exuberantes jardins, proliferavam na área oriental enquanto no extremo ocidental da mancha urbanizada se desenvolvia uma área residencial fortemente marcada pela presença da comunidade inglesa do Porto. É o caso das variadas quintas de recreio construídas ao longo do século XIX em Massarelos, na enconta do Douro, ou ao longo da actual via do Campo Alegre.

Pela sua notoriedade arquitectónica e paisagística muitas destas casas e respectivos jardins foram adquiridos por instituições variadas, alterando-lhes a função inicial de quinta de recreio. É o caso da Quinta de Cima ou da Macieirinha, adjacente ao Palácio de Cristal, onde hoje se 


\section{Revista Convergência Crítica \\ Núcleo de Estudos e Pesquisas em Teoria Social - NEPETS

encontra instalado o Museu Romântico, ou da Quinta do Meio, onde hoje se instala a Casa Tait. Outro exemplo paradigmático é o da Quinta do Campo Alegre: adquirida na década de 1930 pelo Estado Português, e apesar de ter visto ser reduzida drasticamente a sua área para a construção de infraestruturas viárias e desportivas, é actualmente o Jardim Botânico da cidade, propriedade da Universidade do Porto. A mesma Universidade é ainda detentora de outras antigas quintas de recreio adjacentes ao Jardim Botânico, como a Casa Primo Madeira e Casa Burmester. Merece ainda destaque a setecentista Quinta de Santo Ovídeo, propriedade de consideráveis dimensões inserida em plena malha urbana em finais do século XIX. Reconhecida pela grandiosidade e espectacularidade do seu traçado, a Quinta de Santo Ovídeo retrata de forma eloquente as transformações sociais do século XIX. Por um lado por ter sido um dos exemplos mais paradigmáticos do poder da "cidade nova", e dos seus promotores, sobre os símbolos da antiga organização social, quando, designadamente por razões de escassez de rendimento da propriedade, a quinta foi desmembrada para a abertura da Rua Álvares Cabral. Por outro lado, a Quinta de Santo Ovídeo representa o exemplo portuense de uma prática generalizada nas cidades europeias antes da construção de jardins públicos, a abertura dos jardins privados, ocasionalmente e sobre determinadas condições, ao passeio público.

Os jardins privados constituem-se diferentemente na estrutura verde do Porto: têm tempos diferentes mas que se sobrepõem ao longo do século XIX, entre os que são formados ainda segundo o simbolismo de paisagem do século anterior, como o jardim da Quinta de Santo Ovídeo, expressão de um poder sobre a terra e sobre a sociedade que evoca ainda a estrutura social ante-liberal e passa pela expressão plena do espírito do século liberal, como nas casas grandes e grandes jardins do Campo Alegre, tendência de representação do sublime da natureza, que as tendências mais modernizadoras (modernistas) do século seguinte, se ainda incorporam, apresentam também já os primeiros sintomas, como em Serralves, de um kitsch inevitável. Neste âmbito, convém também referir a emulação deste tipo de representação da natureza como sublime romântico que serviria de modelo, em versões menos exuberantes, a alguns dos jardins das moradias de uma classe média que a nova função pública vai engendrado. Contudo, a função agrícola destes espaços dos quintais privados da nova classe média não é nunca totalmente substituído.

Comparando os jardins de Santo Ovídeo, de contornos regulares, desenhando esquemas de simetria, de imediato nos acode a origem setecentista da sua concepção, e assim nos indica de modo directo a origem aristocrata da posse da terra que a estrutura social ante-liberal havia organizado na cidade, em que os dois estados que não o terceiro acumulam a propriedade e a representam de acordo com essa concentração. A uma ínfima escala versailliana, são a expressão clara do século das pragmáticas de etiqueta, do lugar "natural" dos elementos que compunham os grupos sociais, da harmonia forçada de uma sociedade quase inteiramente desprovida de mecanismos de livre mobilidade e ascensão social. Assim, Santo Ovídeo, na planta do Porto do século XIX final é mais o símbolo de um tempo que termina do que a expressão plena do século a que ainda veio pertencer - a sua demolição nos finais do século XIX é porventura, para além de um exercício de ordenamento urbano, a expressão de mobilidade social e de substituição de propriedade (e dos seus símbolos) provocada pela chegada dos novos "donos da terra" - a burguesia. 


\section{Revista Convergência Crítica \\ Núcleo de Estudos e Pesquisas em Teoria Social - NEPETS \\ ISSN 2238-9288}

A burguesia que vai nascer da nova grande indústria e do novo grande comércio exige talvez uma nova forma de organização da terra e de representação da natureza, e por isso de uma nova paisagem cultural urbana (Martins 1992). As casas grandes do Campo Alegre ilustram bem a renovação da paisagem cultural que acompanha a nova e vibrante sociedade que, suportada pelo novo estado liberal, o capitalismo industrial e comercial promove (Torgal et al 1998): ao redor de "palacetes" desenham-se elementos de natureza que indiciam a influência plena do romantismo como demanda do sublime. Espécies exóticas, trazidas das quatro partes do mundo, evocando o carácter cosmopolita de uma actividade industrial e comercial que o colonialismo promove à escala planetária, convivem inesperadamente num mesmo lugar, apresentando-se em parques frondosos, expressão das opulências vegetais dos ambientes tropicais ou florestais do norte da Europa, simulacros de florestas que o mundo do sul da Europa, a que a pertence a cidade do Porto, nunca conheceu, porque a sua história, como a de toda a região a que pertence, é uma história de desflorestação muito antiga, e em que as referências de identidade de natureza mais estáveis se organizam em redor não da sylva mas do ager, da terra cultivada, em que a própria produção de árvores não é livre nem espontânea.

Esta geografia é duplamente estranha à cidade, porque tem origem numa vangloriação romântica mais típica do norte da Europa e usa de uma expressão de um "tropicalismo" colonial (Livingstone 2002; Driver 2004) que se opõe estruturalmente àquela mas não ao Mediterrâneo, espécie de transição entre os dois mundos, e que as nações ibéricas antes daquela haviam contactado. Em todo o caso, Portugal será sensível a esta reapresentação dos trópicos, filtrada pelo cosmopolitismo do norte da Europa, e que será a matriz de reactivação da presença portuguesa em África (Pimenta 2010).

\section{Periferias rurais}

Um olhar de relance sobre o mapa do Porto dos fins do século XIX (Figuras 1 e 4) revela uma forte presença da estrutura verde. A uma cidade densa, antiga, herdeira do burgo em tempos muralhado, encostam-se os campos que quase ininterruptamente se estendem até ao rosário de povoados que organizam o espaço rural circundante.

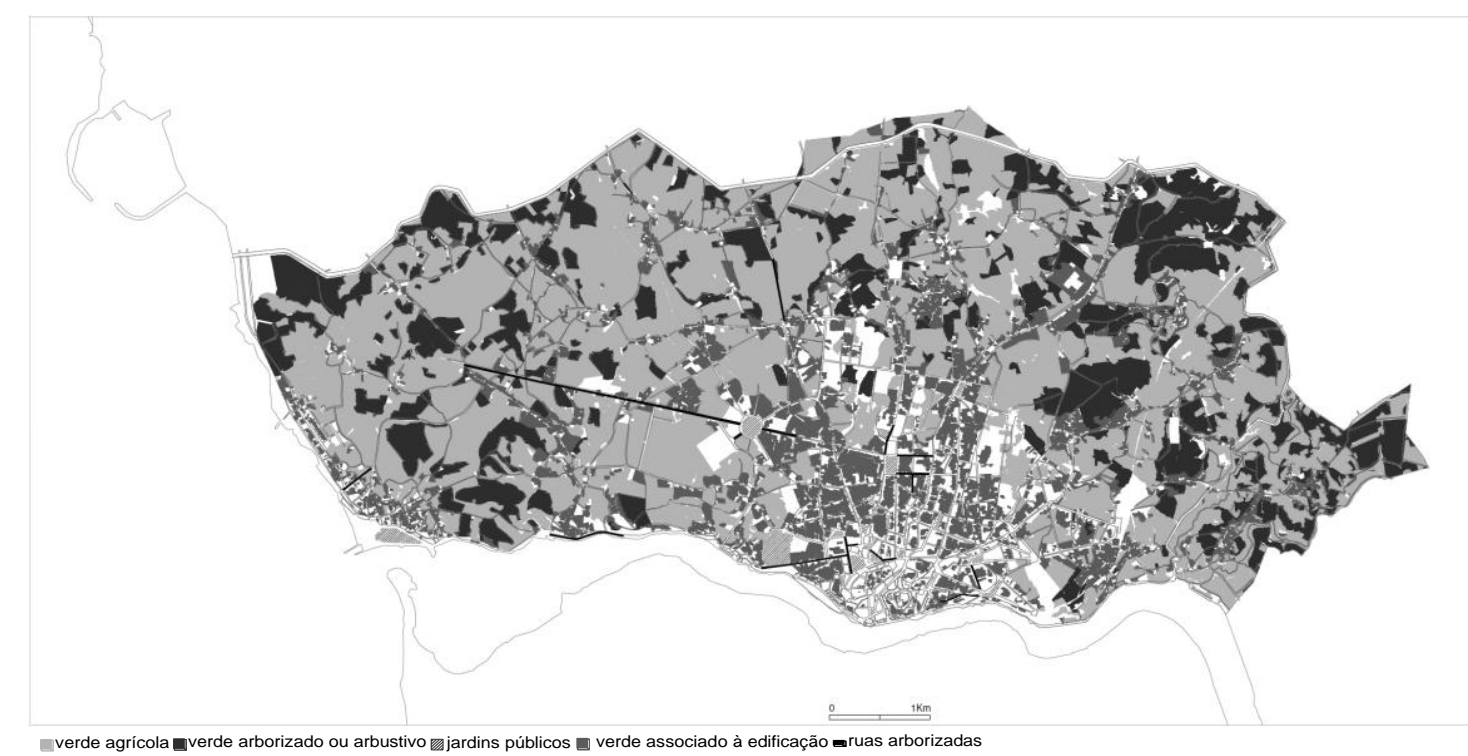




\section{Revista Convergência Crítica \\ Núcleo de Estudos e Pesquisas em Teoria Social - NEPETS \\ ISSN 2238-9288}

Figura 4 - Porto: as periferias rurais. (Fonte: Madureira 2001-2002, adaptado)

Contudo, é necessário fazer referência não apenas à exploração da terra agrária e sua função de ager da urbs, mas também da posse da terra que o organiza. A este respeito são especialmente importantes as quintas.

\subsection{Quintas}

As quintas de recreio, assim denominadas por, apesar de continuarem invariavelmente a preservar a produção hortícola, serem concebidas de forma a torná-las espaços de lazer, fruição e também de ostentação, tinham uma expressão significativa no Porto oitocentista, designadamente no seu anel periférico rural.

Havendo menções a quintas de recreio construídas em épocas anteriores, como a Quinta do Prado, construída para recreio dos prelados em finais do século XVI e entretanto transformada num dos grandes cemitérios da cidade, é no século XVIII que se verifica um grande incremento na construção de quintas (Andresen, Marques 2001). Nicolau Nasoni, artista e arquitecto italiano, foi o responsável pelo projecto de variadas dessas quintas de recreio, difundindo na cidade novos conceitos de composição paisagística, designadamente a preocupação de subordinar a composição da quinta a um eixo de simetria (Araújo 1979). Constituem importantes exemplos as setecentistas quintas do Freixo, da Bonjóia, da Prelada, de Ramalde e do Chantre. Já no século XIX, destaque-se a contribuição de Alfredo Allen (1828-1907), não só pelo seu profundo interesse na arte dos jardins, que procurou intensamente divulgar, mas também por ter sido responsável pela construção da quinta de Vilar d'Allen, considerada um marco na história dos jardins no norte de Portugal por representar a introdução do novo gosto da arte dos jardins oitocentistas. Este século não foi tão pródigo na construção de novas quintas de recreio, mas todos estes espaços de requinte e ostentação permaneceram ao longo do século, pontuando, contrastando e contribuindo para organizar, o anel rural da cidade.

A concentração da posse da terra é uma condição inerente à evolução da Idade Moderna. Em Portugal, até às modificações conjunturais do primeiro século XIX (posse da terra sobretudo dependente da sorte das armas durante a guerra civil) e das transformações estruturais do segundo século XIX (concentração "capitalista" da terra), a concentração da terra havia progressivamente beneficiado os "grandes" da Igreja e da aristocracia, razão porque podemos ver que algumas das quintas (e.g. o Freixo) que enquadravam o mundo rural junto à cidade têm se não origem pelo menos grande desenvolvimento no século ante-liberal. Esta é uma paisagem cultural de representação explícita: os planos de vista, o poder cénico, a exclusão espacial, tudo se associa num simbolismo da terra de permanência e harmonia impostos pela organização das relações sociais; a mobilidade social é praticamente inexistente e, tal como na produção geométrica da natureza, também a sociedade é sujeita a uma surveillance de forte proximidade.

O século "liberal" produzirá naturalmente uma enorme perturbação neste mundo de "harmonia" e hierarquia. Com os soldados franceses iriam chegar as primeiras ideias revolucionárias e de novos impérios que já não nos deixariam com a partida daqueles. Fixar-se-ão os gostos das novas elites liberais, a que a dominação britânica, de direito e de facto, emprestará um cunho tory ainda mais marcado. 


\section{Revista Convergência Crítica \\ Núcleo de Estudos e Pesquisas em Teoria Social - NEPETS}

Este movimento de repaisajamento da cidade levado a cabo pelas novas elites irá traduzir-se numa produção de espaço e natureza com reconhecíveis elementos neo-paladianos ou genericamente neo-clássicos (Pereira, Serén 1994), que são também a expressão de uma relação "colonial" sui generis da comunidade britânica que a cidade progressiva mas incompletamente incorpora como sua. Esta transformação exprimir-se-á em elementos edificados do centro urbano e nas quintas da cidade, estas mimeticamente relacionadas com uma idêntica transformação que animava as quintas do vale do Douro, que a mesma burguesia estrangeira do Porto possui. É uma "paisagem colonial" de que se trata em muitos casos, mas uma colonização que em parte se integra e se torna consubstancial à cidade. Em muitos aspectos, as quintas do Porto possuem o mesmo detachment com a cidade que detêm os modelos originais do country inglês: os elementos de distanciação são incorporados na produção de natureza e no simbolismo dos elementos decorativos (em que traços de orientalismo são tornados conspícuos [Said 1978; Bhabha 2004]). Estas quintas, que a produção do vinho do Porto aproxima das do vale do Douro, relação que se torna graficamente explícita na inscrição dos nomes das famílias nas quintas e nos armazéns da ribeira de Gaia, então apenas um entreposto comercial entre a cidade e o campo, serão a expressão espacial de uma elite e palco privilegiado da reprodução social e simbólica da paisagem cultural urbana do Porto oitocentista, pelo menos até às transformações profundas causadas pela irreprimível acumulação capitalista do terceiro quartel do século XIX.

\subsection{Campos}

Um breve relance pelo mapa do Porto dos finais do século XIX é também suficiente para que nos apercebamos de que esta é uma cidade ainda plenamente penetrada pela vida rural. Com a excepção da cidade antiga, em tempos muralhada, e dos eixos viários principais que a ligam ao exterior, o campo está presente em todo o lado e encosta-se intimamente ao flanco das colinas da cidade de planta densa. Todas as actuais freguesias periféricas da cidade são então vastas extensões de exploração agrícola, ou seja, como no modelo urbano arcaico que a Europa conhece desde a Idade Média (McCormick 2001), o campo que abastece, alimenta a cidade.

É importante reconhecer este elemento camponês na organização da cidade, assim como a sua expressão espacial e a metamorfose que se originará com a modernização do século XIX. Será sobre estes campos que se lançarão os caminhos do novo progresso, o caminho-de-ferro, sobretudo na parte oriental da cidade, assim como nele, neste mesmo campo, se edificarão as grandes unidades industriais que irão contribuir para o rápido preenchimento do ensanche da cidade, essa corola semi-rural que se estendia desde os velhos limites da muralha até aos núcleos plenamente rurais da periferia. Podemos lê-las ainda hoje, ao avistarmos algumas das altas torres de brick vermelho que indicam os fornos de carvão que alimentavam aquelas unidades industriais. Elas são como que o sinal da proletarização progressiva da cidade, e esse é o seu principal valor simbólico na paisagem cultural urbana do Porto e da transformação associada da sua estrutura e ideia de natureza. Representam a metamorfose irreversível da intemporalidade quási-feudal da posse da terra agrária para o enxameamento proletário do espaço urbano operário da cidade. Este movimento de transformação tem uma expressão espacial correspondente e uma "ecologia da exaustão" associada - as ilhas.

As ilhas do Porto não são um exclusivo do século XIX industrial, mas é com ele que adquirem os atributos com que vêm a caracterizar conspicuamente parte da paisagem urbana; e é sobretudo durante este século, e sobretudo a sua parte final, que a ecologia da exaustão é levada 


\section{Revista Convergência Crítica \\ Núcleo de Estudos e Pesquisas em Teoria Social - NEPETS \\ ISSN 2238-9288}

ao extremo. As ilhas são uma ocupação densa, continuada, cumulativa, de quintais e terras cultivadas, de terrenos incultos, que se preenchiam ou intercalavam na malha urbana edificada. A ocupação destes retalhos de vida rural pelas famílias operárias dependentes das novas indústrias é bem a expressão deste momento-chave de modernização e industrialização da cidade ao longo da parte final do século XIX e parte do século seguinte. E é de uma verdadeira exaustão ecológica de que se trata, porque, se fizermos excepção da cidade intramuros medieval, são as únicas áreas da cidade que serão sistematicamente desprovidas de elementos de estrutura verde e, de um modo genérico, os lugares em que o controlo dos elementos de natureza, a salubridade do ar, a potabilidade das águas, é pressionado ao limite de resistência ecossistémica. Por efeito da exploração social que a nova economia exige, o espaço operário tornar-se-á progressiva e concomitantemente exíguo, sombrio, insalubre. E assim - com nos séculos medievais a peste se adequava intimamente aos bairros mais insalubres - o mapa das ilhas da cidade irá marcar, com um impressionante rigor de sobreposição cartográfica, o desenho na planta da cidade das doenças mortalmente contagiosas, entre todas a tuberculose.

Na produção de espaço e de natureza que lhes é tornado inevitável pelas relações sociais que a modernização exige, as ilhas do Porto, que ainda hoje se reconhecem em algumas áreas da cidade, detêm o poder simbólico único de guardarem na paisagem cultural urbana a demonstração da iniquidade da exploração dos homens, mulheres e até crianças pelos seus semelhantes, bem como a complacência da cidade inteira.

\section{Conclusão}

Se, como assevera Goethe, "o moderno é o de sempre", então a história da modernização de uma cidade não tem um princípio nem um fim definitivo. Se o século XIX final e o princípio do seguinte constituem um momento de aceleração económica e mobilidade social intensas, também a sua percepção nos é ditada pela representação que fazemos de que esse momento constitui a origem do agora somos como cidade contemporânea. Em cada época, porém, a modernização da cidade foi sendo levada a cabo, com ritmos talvez diferentes mas sempre resultando do encontro e conflito entre a produção do espaço e da natureza, a representação das suas paisagens e a prática concreta dos seus lugares (Livingstone 2003).

\section{Bibliografia}

Andresen,T., Marques, T. (2001). Jardins Históricos do Porto. Lisboa: Inapa.

Araújo, I. (1979). Jardins, Parques e Quintas de Recreio no Aro do Porto, Revista de História, Vol. II, 375-388.

Benjamin, W. (1997) Charles Baudelaire. New York: Verso.

Bhabha, H. (2004) The location of culture (reimp.). London e New York: Routledge

Câmara Municipal do Porto (CMP) (1992). Uma Cartografia Exemplar. O Porto em

1892. Exposição Comemorativa do $1^{\circ}$ Centenário da Carta Topográfica da A. G.

Telles Ferreira. Porto: CMP.

Capel, H. (2002). Jardines y parques en la ciudad. Ciencia y estética. Ciencias, 68, 4-16. 
Cosgrove, D. (1998) Social Formation and Symbolic Landscape. Madison: Wisconsin University Press.

Cosgrove, D., Daniels, S., eds (1988) The Iconography of Landscape. Cambridge: Cambridge University Press.

Driver, F. (2004) 'Imagining the Tropics: Views and visions of the tropical world', Singapore Journal of Tropical Geography, 25(1), 1-17.

Livingstone, D. N. (2002) 'Race, space and moral climatology'. Journal of Historical Geography 28 (2): 159-180.

Livingstone, D. N. (2003) Putting science in its place. Geographies of scientific knowledge. Chicago: Chicago University Press.

Madureira, H. (2001-2002) 'Processos de transformação da estrutura verde do Porto'. Revista da Faculdade de Letras da Universidade do Porto, 17-19: p. 137-218.

Madureira, H., Andresen, T., Monteiro, A. (2011). Green structure and planning evolution in Porto. Urban Forestry \& Urban Greening, doi:10.1016/j.ufug.2010.12.004

Martins, L. (1992). 'Do passeio público ao "jogo de cartas": apontamentos sobre os espaços ajardinados do Porto'. Actas do VI Colóquio Ibérico de Geografia, 627640.

Matos, F. L., Rodrigues, R. (2009) 'As ilhas do Porto, lugares de resistência'. Observatorium 1 (1): 33-57.

McCormick, M. (2001) Origins of the European Economy. Communications and Commerce, 300-900. Cambridge: Cambridge University Press.

Oliveira, J. (1973) O espaço urbano do Porto, condições naturais e desenvolvimento. Coimbra: Centro de Estudos Geográficos

Pereira, G., Serén, M. C. (1994) - 'O Porto oitocentista'. In O. Ramos (ed.). História do Porto. Porto: Porto Editora.

Pimenta, J. R. (2010) 'Portuguese colonial geographical tradition'. Africana Studia, 14: p. 313-322.

Said, E. (1978) Orientalism. London: Routledge.

Schama, S. (1995) Landscape and Memory. New York: A. Knopf.

Shapin, S. (1991) “"The Mind Is Its Own Place”. Science and Solitude in SeventeenthCentury England'. Science in Context, 4 (1): 191-218. 


\section{Revista Convergência Crítica \\ Núcleo de Estudos e Pesquisas em Teoria Social - NEPETS

Silva, F. (1994) 'Tempos Modernos'. In L. O. Ramos (ed.). História do Porto. Porto: Porto Editora.

Teixeira, M. (1996) Habitação Popular na Cidade oitocentista: as ilhas do Porto. Lisboa: Fundação Calouste Gulbenkian e Junta Nacional de Investigação Científica e Tecnológica.

Tester, K. (1995) The flâneur. Routledge: London.

Torgal, L. R., J. A. Mendes e F. Catroga, coord. (1998). História da História de Portugal. 1. A história através da história. S.1.: Temas e Debates. 